\title{
SUPPRESSION OF OVERWINTERING BOTRYTIS CINEREA INOCULUM ON GRAPE RACHII USING ANTAGONISTIC FUNGI
}

\author{
S.R. FOWLER ${ }^{1}$, M.V. JASPERS ${ }^{1}$, M. WALTER ${ }^{2}$ \\ and A. STEWART ${ }^{1}$ \\ ${ }^{I}$ Soil, Plant and Ecological Sciences Division, PO Box 84, \\ Lincoln University, Canterbury \\ ${ }^{2}$ The Horticulture and Food Research Institute of New Zealand Ltd., \\ PO Box 51, Lincoln
}

\begin{abstract}
Seven fungi were assessed for ability to suppress infection and sporulation of $B$. cinerea on sterilised grape rachii at 5, 10, 15 and $20^{\circ} \mathrm{C}$. At $10-20^{\circ} \mathrm{C}$, conidium production of $\mathrm{B}$. cinerea was suppressed by all test isolates. The most effective Epicoccum, Scytalidium and Ulocladium isolates had conidium germination frequencies and germ tube growth rates greater than or comparable to that of $B$. cinerea at 10$25^{\circ} \mathrm{C}$. Epicoccum and Ulocladium isolates were further tested for their ability to reduce overwintering $B$. cinerea on rachii in two vineyards. Their suppression of $B$. cinerea was low and inconsistent, but results were confounded by low $B$. cinerea levels in all treatments, possibly due to unseasonably warm, dry winter weather.

Keywords: Bunch rot, biological control, Epicoccum, Ulocladium, Scytalidium.
\end{abstract}

\section{INTRODUCTION}

Botrytis cinerea Pers., the fungal pathogen causing 'Botrytis rot' in a wide range of soft fruit crops, frequently causes significant losses in grape crops, particularly if wet weather occurs just prior to harvest (Nicholas et al. 1994). The pathogen survives between crops as a saprophyte on necrotic tissues and may also remain dormant in residues of rotted bunches, grape mummies and as sclerotia on dormant infected canes. Disease management methods in winter, which include removal of dead or diseased crop debris, can reduce inoculum levels within vineyards the following season. During the growing season, disease control is commonly based upon repeated applications of a narrow range of fungicides and the use of pruning and training techniques to increase air movement within vine canopies (Emmett and Nair 1991). However, increasing problems with fungicide resistance and concerns about pesticide residues have contributed to a worldwide move towards more sustainable disease control methods, which requires the development of new strategies such as biological control.

Research into the use of antagonistic fungi for the control of $B$. cinerea has identified a number of promising species, of which some isolates were recently shown to suppress the bunch rot stage of the disease in vineyard trials (Stewart et al. 1998). The work described here reports laboratory-based investigations and field trials which evaluated the ability of a number of fungal isolates, including those tested by Stewart et al. (1998), to suppress the pathogen in overwintering grape rachii.

\section{Grape rachis bioassay}

\section{MATERIALS AND METHODS}

Three fungi, isolated from Pinot noir grape rachii after harvest in April 1998 and identified with standard taxonomic keys as Epicoccum sp. (labelled ' 1 ' in this study), Scytalidium sp. and Tricothecium roseum, were found to suppress sporulation of $B$. cinerea in preliminary challenge experiments (similar to those described below). 
These three isolates and a further four, Trichoderma spp. (13 and 16), Epicoccum sp. (21) and Ulocladium sp. (13), which had earlier been found to suppress Botrytis bunch rot (Stewart et al. 1998), were used in challenge experiments on grape rachii against $B$. cinerea. The $B$. cinerea inoculum used consisted of four isolates, originally from grapes and labelled as 'B1', 'B2', 'B4', and 'B7', mixed in equal parts. Cultures of all fungal isolates were maintained on potato dextrose agar (Gibco PDA) slopes at $5^{\circ} \mathrm{C}$.

Cultures of isolates were grown on PDA at $20^{\circ} \mathrm{C}$ under a $12 \mathrm{~h}$ diurnal photoperiod for 2 weeks. Conidial suspensions were made by harvesting conidia in aqueous Tween 80 solution ( 1 drop in $100 \mathrm{ml}$ water) and filtering the suspensions through coarse muslin to remove mycelial fragments. Grape rachii, collected from the Lincoln University research vineyard, were cut into $15-20 \mathrm{~mm}$ long pieces and sterilised with gamma irradiation (27.5 kGy) by Schering-Plough, Animal Health Limited, Upper Hutt. The rachii were dipped into conidial suspensions $\left(1 \times 10^{5}\right.$ conidia/ml $)$ of test isolates for $5 \mathrm{~s}$, dried for $10 \mathrm{~min}$ on paper towels and then sprayed for $1-2 \mathrm{~s}$ with the mixed $B$. cinerea conidial suspension $\left(1 \times 10^{4}\right.$ conidia/ml). For each test isolate, 15 rachii were treated and placed on a tray lined with a sterile moistened paper towel and enclosed in a plastic bag. A $7 \times 3 \times 4$ factorial experiment was set up in which trays of rachii treated with each of the seven test isolates were prepared for each of three grape cultivars (Merlot, Pinot noir and Chardonnay) and incubated at each of four temperatures $\left(5,10,15\right.$ and $\left.20^{\circ} \mathrm{C}\right)$ under a $12 \mathrm{~h}$ diurnal photoperiod. Rachii were incubated for 3 weeks and assessed visually, using a stereo microscope, for $B$. cinerea conidiophore production after 7 and 28 days. The individual rachii were divided into 20 equal sized sections (by visual dissection) and each was assigned a numerical grade according to the number of $B$. cinerea conidiophores present ( 2.5 for $0-5,12.5$ for 5-20 and 25 for more than 20 conidiophores). The 'inoculum potential' of each rachis was the sum of all numerical grades for that rachis. Data were analysed by factorial ANOVA and Fisher's LSD tests, using the statistical package Systat.

\section{Effect of temperature on conidium germination and germ tube elongation}

Conidial suspensions of the test isolates and $B$. cinerea were prepared as described above and four droplets of each were placed equidistantly on water agar plates. For each fungal isolate, six plates were prepared, one for each of the six incubation temperatures, $5,10,15,20,25$ and $30^{\circ} \mathrm{C}$. Percentage germination was determined by observing 50 randomly selected conidia at 3,6,12 and $24 \mathrm{~h}$, and germ tube length for five randomly selected conidia was measured at $24 \mathrm{~h}$. Data were analysed by factorial ANOVA for repeated measures and Fisher's LSD tests, using the statistical package Systat.

\section{Reduction of overwintering $B$. cinerea on grape rachii in the field}

Conidial suspensions $\left(1 \times 10^{5}\right.$ conidia/ml) of the mixed $B$. cinerea cultures and those of the antagonists, Epicoccum (21) and Ulocladium (13), were prepared as above. Treatments were applied at the end of harvest, on 13 April 1998 in the Lincoln University research vineyard, and 26 April 1998 in the Twin Rivers Estate vineyard, Napier. At each site, 10 replicate Pinot noir vines, 30 rachii on each, were randomly selected for each of the following treatments: (a) water control with no inoculation by any fungi, (b) water plus B. cinerea, (c) Epicoccum (21) plus B. cinerea, and (d) Ulocladium (13) plus $B$. cinerea. Water and conidial suspensions of test fungi were applied by dipping rachii into them, in situ, for 2-4 s. After being allowed to dry for $30 \mathrm{~min}$, the rachii were sprayed with the $B$. cinerea conidial suspension to run-off. Dried rachii were covered with netlon bags (Pacspec, Cambridge) and these were left within the vines until pruning (July 1998). Rachii within their bags were then removed and the bags were pinned to the soil surface under vines with wire staples. Assessment for presence of $B$. cinerea on rachii was conducted immediately after application of treatments and at four (Lincoln) or five (Napier) one-monthly intervals to August 1998. At sampling, four rachii selected at random were removed from each vine. Rachii were incubated on trays (lined with moist paper towels and enclosed within plastic bags) at room temperature for one week. Inoculum potential was assessed as described for the rachis bioassay and results were analysed by factorial ANOVA for repeated measures and Fisher's LSD tests, using the statistical package Systat. 


\section{Grape rachis bioassay}

\section{RESULTS}

All fungal isolates tested reduced $(\mathrm{P}<0.05)$ the development of $B$. cinerea conidiophores on inoculated rachii, at 10,15 and $20^{\circ} \mathrm{C}$, with no differences $(\mathrm{P}>0.05)$ between these temperatures. At $5^{\circ} \mathrm{C}$, too few conidiophores developed on rachii of the control treatment, so effects of the test isolates could not be determined (Fig. 1). The effect of cultivar type was not significant $(\mathrm{P}>0.05)$ although there was a trend for a greater degree of conidiophore production in the more susceptible cultivars, Pinot noir and Chardonnay, than the more resistant cultivar Merlot. The differential suppression of conidiophore production by some fungal species reflected this trend in susceptibility and was also temperature dependent, resulting in an interaction $(\mathrm{P}<0.05)$ between cultivar, temperature and fungal isolates. For example, Tricothecium roseum the least effective isolate did not reduce conidiophore production on Pinot noir at $15^{\circ} \mathrm{C}$ or on Chardonnay at $20^{\circ} \mathrm{C}$, but did on the other treatments. For all cultivars and temperatures $10-20^{\circ} \mathrm{C}$, suppression of $B$. cinerea conidiophore production on treated rachii was greatest for the isolates, Epicoccum sp. (1), Scytalidium sp. and Ulocladium sp. (13) and least for Tricothecium roseum $(\mathrm{P}<0.05)$.

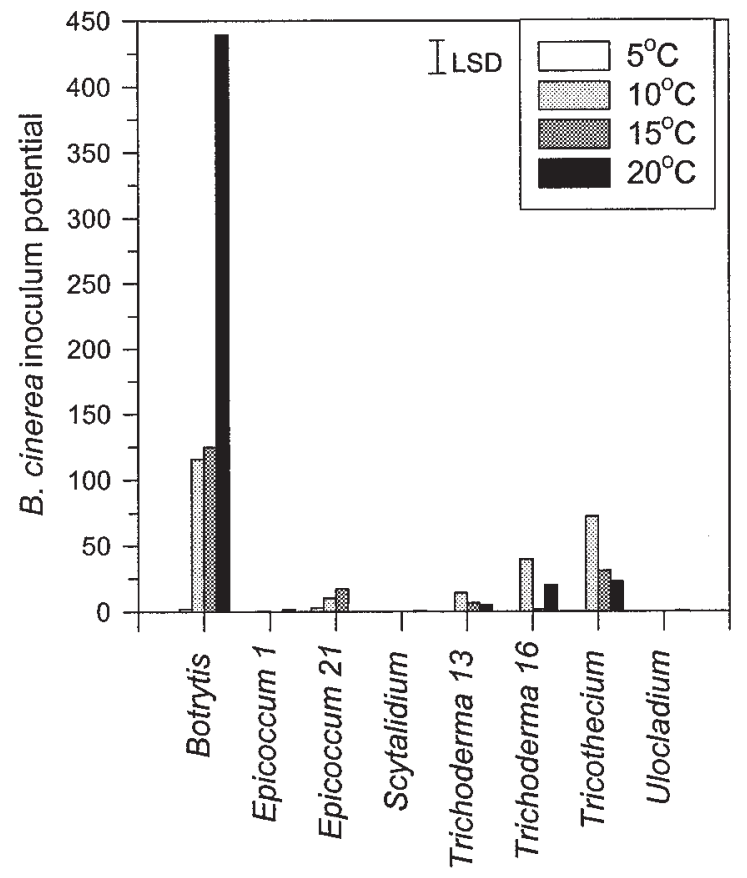

FIGURE 1: Botrytis cinerea inoculum potential on grape rachii treated first with test fungi and then with $B$. cinerea, incubated at $5-20^{\circ} \mathrm{C}$. Inoculum potential $=$ sum of assessments of conidiophore abundance.

\section{Effect of temperature on conidium germination and germ tube elongation}

Germination and germ tube elongation (Fig. 2) was influenced by temperature $(\mathrm{P}<0.05)$. Germination did not occur at the extremes of the range, 5 and $30^{\circ} \mathrm{C}$, for conidia of $B$. cinerea, or at the cooler temperatures, for Epicoccum sp. (21) $\left(5-15^{\circ} \mathrm{C}\right)$, Trichoderma sp. (13) $\left(5-10^{\circ} \mathrm{C}\right)$ and Trichoderma sp. $(16)\left(5^{\circ} \mathrm{C}\right)$. At temperatures 10- 
$25^{\circ} \mathrm{C}$, germination frequencies were similar $(\mathrm{P}<0.05)$ to those of $B$. cinerea, for all test fungi except Epicoccum sp. (21) and Trichoderma sp. (13). Germ tube elongation was affected by temperature $(\mathrm{P}<0.05)$, with the test fungi showing different responses to temperatures within the range tested (Fig. 2). Germ tube growth was similar $(\mathrm{P}<0.05)$ to that of $B$. cinerea for all isolates except Scytalidium sp., Tricothecium roseum, and Ulocladium sp. (13), for which rates of growth were greater $(\mathrm{P}<0.05)$ than for B. cinerea at $10-25^{\circ} \mathrm{C}, 15-25^{\circ} \mathrm{C}$ and $15-25^{\circ} \mathrm{C}$ respectively.

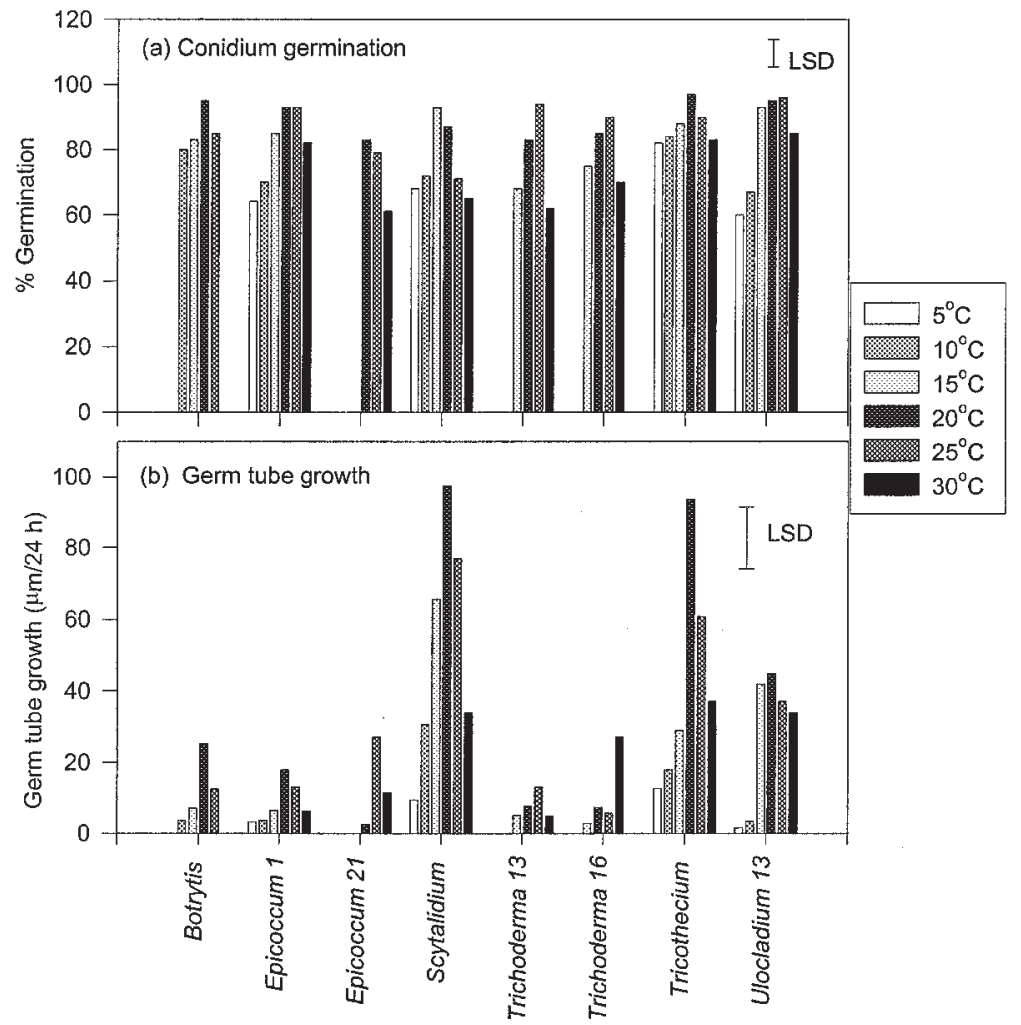

FIGURE 2: (a) Mean percent germinated conidia and (b) mean germ tube length $(\mu \mathrm{m}$ in $24 \mathrm{~h})$, for test fungi grown on agar at different temperatures.

Reduction of overwintering inoculum of $B$. cinerea on grape rachii in the field

Treatment of rachii with the antagonists Epicoccum sp. (21) and Ulocladium sp. (13) had different effects at Napier and Lincoln. At Napier, they gave no significant suppression of conidiophore production at any of the assessment times and had no effect overall $(\mathrm{P}>0.05)$. However, at Lincoln, both antagonists caused an equal reduction in $B$. cinerea conidiophore production compared to the control which had been treated with only $B$. cinerea conidia. This effect was significant $(\mathrm{P}<0.05)$ overall and for the individual assessments, immediately after application and at one and two months, but not at three and four months after application (Fig. 3). 


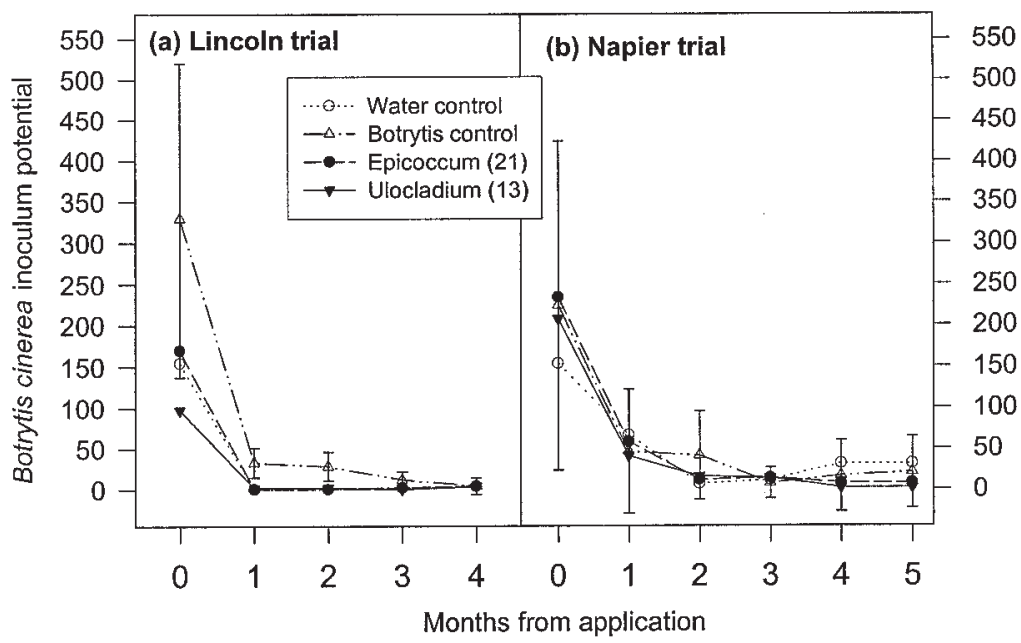

FIGURE 3: Botrytis cinerea inoculum potential on grape rachii, in field trials at (a) Lincoln and (b) Napier. Rachii were treated first with test fungi and then with $B$. cinerea. For clarity, error bars (5\% LSD) are shown only for the Botrytis control.

\section{DISCUSSION}

In this study, the fungal isolates most effective at suppressing $B$. cinerea were Epicoccum sp. (1), Scytalidium sp. and Ulocladium sp. (13). These isolates also showed germination percentages and germ tube elongation rates equal to or greater than those of B. cinerea. The exception was Tricothecium roseum, which had high rates of germination and germ tube growth but was the least effective in suppressing sporulation of $B$. cinerea on rachii. The results suggest that it may have been the ability of these isolates to germinate and colonise rachis tissues with equal or greater speed than $B$. cinerea which contributed to their success in suppressing the pathogen. Research into biocontrol modes of action of fungi from these genera indicates that competitive ability may be one of the means by which they are able to become the dominant species on a substrate (Köhl et al. 1995). A number of Epicoccum species have been shown to outcompete numerous pathogenic fungi (Boland and Hunter 1988) and to produce antifungal compounds (Zhou et al. 1991). Species of Scytalidium and Ulocladium have been reported to be effective biological control agents on substrates in which they were able to become dominant species. A lack of evidence of parasitic behaviour or production of antifungal compounds by these fungi has led to the conclusion that competitive ability is their most likely mode of action (Currie and Hiratsuka 1996; Köhl et al. 1995).

In order for potential antagonists to reduce the level of overwintering $B$. cinerea inoculum on rachii, it is essential that they have the ability to survive and/or grow as well as or better than the pathogen in the winter temperature and moisture conditions commonly found in New Zealand. There is little evidence in the literature on the cool temperature biocontrol capabilities of these fungal genera. Epicoccum purpurascens was reported (Hannush and Boland 1996) to completely suppress grey mould on beans, caused by $B$. cinerea, under combinations of 20,24 , and $28^{\circ} \mathrm{C}$ and relative humidity of 90,95 and $100 \%$, respectively. High rates of biocontrol activity by Ulocladium species, which resulted in suppression of $B$. cinerea and B. allii sporulation, was reported under conditions of interrupted leaf wetness. In the field, germination rates for conidia of 
U. atrum, determined $18 \mathrm{~h}$ after field application, varied between 0 and $99 \%$, depending on duration of leaf wetness (Köhl et al. 1995). However, the laboratory studies reported here, on conidium germination and germ tube growth, showed that species of Epicoccum, Scytalidium, Trichoderma, Tricothecium and Ulocladium were able to germinate at temperatures likely to occur in New Zealand vineyards, but the effects of fluctuations in temperature and other environmental stresses were not examined.

To determine whether the antagonists found by Stewart et al. (1998) to suppress Botrytis bunch rot were able to suppress the pathogen in overwintering rachii, two field trials were set up to test Epicoccum sp. (21) and Ulocladium sp (13). Although these fungi were able to reduce $B$. cinere $a$ conidiophore production and/or colonisation of grape rachii at the Lincoln trial in the first two months following harvest, these reductions were not maintained through to early spring. Furthermore, at Napier, reductions in sporulation/colonisation were not significant $(\mathrm{P}>0.05)$. The observed failure of the antagonists to bring about continued reduction of $B$. cinerea inoculum levels may well have been a reflection of the low inoculum levels in the control treatment, rather than loss of activity on the part of the antagonists. Artificial inoculation with $B$. cinerea conidia failed to increase inoculum levels above the background levels initially determined, indicating that the conditions experienced in both trials were not conducive for Botrytis colonisation of the rachii. This may have been due to the occurrence of warmer $\left(1-2^{\circ} \mathrm{C}\right.$ greater than usual) mean winter temperatures and abnormally dry (50-70\% less rainfall than average) weather conditions (McGill and Burgess 1998), since the low humidities experienced would clearly have reduced conidium germination and establishment of $B$. cinerea. The requirement by this pathogen for moist conditions is well-known (Nicholas et al. 1994). It is also possible that the optimum time for application of antagonists may be later than that used in this trial, ie. directly after harvest. Establishment of $B$. cinerea and antagonistic fungi on rachii in the field may be considerably greater when numbers of other saprophytic competitors have been reduced by winter temperatures and at a time when temperatures and moisture levels increase again in spring.

Grape rachii are thought to represent one of the more important overwintering sites for B. cinerea (Emmett and Nair 1991), in which case the low rates of infection observed in this study may be normal and sufficient to bring about spring infection of grape tissues. It is also possible that other grape tissues and vineyard trash may provide overwintering sites for the pathogen, in addition to or of greater significance than rachii. These questions need to be addressed in future investigations so that a fuller understanding of the primary spread mechanisms of $B$. cinerea can lead to development of more effective control strategies against this disease.

\section{ACKNOWLEDGEMENTS}

The authors wish to thank Winegrowers of New Zealand and the Foundation for Research, Science and Technology, New Zealand for partial funding of this project and also Twin Rivers Vineyard for use of their vines. We are grateful for the statistical assistance given by Dr Chris Frampton (Lincoln University) and fungal identification provided by Dr Ian Harvey (Plantwise).

\section{REFERENCES}

Boland, G.J and Hunter, J.E., 1988. Antagonism of white mold (Sclerotinia sclerotiorum) of bean by fungi from bean and rapeseed flowers. Can. J. Plant Path. 67: 1775-1781.

Currie, C.R. and Hiratsuka, Y., 1996. Evaluating insect-mediated dispersal of Scytalidium uredinicola for biological control of western gall rust. Can. J. Forest Res. 26: 1754-1760.

Emmett, R.W. and Nair, N.G., 1991. Botrytis rot of grapes in Australia. Australian Grapegrower and Winemaker 33: 19-21.

Hannusch, D.J. and Boland, G.J., 1996. Interactions of air temperature, relative humidity and biological control agents on grey mold of bean. Eur. J. Plant Path. 102: 133-142. 
Köhl, J., Molhoek, W.M.L., Fokkema, N.J. and Van der Plas, C.H., 1995. Effect of interrupted leaf wetness periods on suppression of sporulation of Botrytis allii and Botrytis cinerea by antagonists on dead onion leaves. Eur. J. Plant Path. 101: 627-637.

McGill, K. and Burgess, S., 1998. New Zealand Climate Digest. Institute of Waste and Atmospheric Research Ltd, Wellington, New Zealand.

Nicholas, P., Magarey, P. and Wachtel, M. (eds)., 1994. Diseases and Pests - Grape Production Series. Winetitles Adelaide, pp 17-21.

Stewart, A., Antonov, A., Trought, M. and Walter, M., 1998. Biological control of Botrytis bunch rot of grapes using naturally occurring fungal antagonists. Proc. 7th Int. Cong. Plant Path. Edinburgh, August. Abstract p73.

Zhou, T. Reeleder, R.D. and Sparace, S.A., 1991. Interaction between Sclerotinia sclerotiorum and Epicoccum purpurascens. Can. J. Bot. 69: 2503-2510. 